\title{
Isolation and Culture of Neurospheres for the Study of Pathogenesis of Prion Disease
}

Yoshifumi Iwamaru ${ }^{1}$, Takato Takenouchi ${ }^{2}$ and Hiroshi Kitani ${ }^{*}$

${ }^{1}$ Influenza and Prion Disease Research Center, National Institute of Animal Health (NIAH),

Tsukuba, Japan; ${ }^{2}$ Division of Animal Sciences, National Institute of Agrobiological Sciences,

Tsukuba, Japan

*For correspondence: kitani@affrc.go.jp

[Abstract] Neurosphere contains neural stem cells that are capable of self-renewal and multilineage differentiation including neurons, astrocytes, and oligodendrocytes (Gage, 2000). Cell culture model using differentiated neurosphere cultures are suggested to be a valuable tool for studying the pathogenesis of prion disease at the cellular level (Iwamaru et al., 2013). This protocol describes the procedure for a culture of whole brain-derived neurospheres from newborn mouse brains. Neurosphere formation steadily occurs within a week from the cultures of neonatal whole brains and these cells have stem cell properties.

\section{Materials and Reagents}

1. Newborn mice (age at one day after birth)

Present culture method can be applied to any mouse strains, regardless of sex. We used prion protein overexpressing transgenic mouse and prion protein-deficient mouse for our present study (Iwamaru et al., 2013).

2. Dulbecco's phosphate buffered saline without $\mathrm{Ca}$ and Mg (D-PBS) (Nacalai Tesque, catalog number: 14249-95)

3. Di-sodium dihydrogen ethylenediamine tetraacetate dihydrate (EDTA) (Nacalai Tesque, catalog number: 151-11)

4. Hank's balanced salt solution (HBSS) (Sigma-Aldrich, catalog number: H8264)

5. Dulbecco's modified Eagle's medium/nutrient mixture F-12 Ham (DMEM/F12 Ham) (Sigma-Aldrich, catalog number: D8437)

6. N-2 supplement (Life Technologies, catalog number: 17502-048)

7. Penicillin-Streptomycin (Sigma-Aldrich, catalog number: P0781)

8. Fetal bovine serum (FBS) (Hyclone, catalog number: $\mathrm{SH} 30070.03$ )

9. Accutase (Innovative Cell Technologies, catalog number: AT104)

10. Trypsin (Sigma-Aldrich, catalog number: T8003) (see Recipes)

11. Deoxyribonuclease I (DNase I) (Worthington Biochemical Corporation, catalog number: 


\section{LS002139) (see Recipes)}

12. Epidermal growth factor human (EGF) (Sigma-Aldrich, catalog number: E9644) (see Recipes)

13. Fibroblast growth factor-basic human (bFGF) (Sigma-Aldrich, catalog number: F0291) (see Recipes)

14. Bovine serum albumin (BSA) (Sigma-Aldrich, catalog number: A9576) (see Recipes)

15. Neurosphere basal medium (see Recipes)

\section{Equipment}

1. Falcon $15 \mathrm{ml}$ conical centrifuge tube (Corning, catalog number: 352096 )

2. Falcon $100 \mathrm{~mm}$ cell culture dish (Corning, catalog number: 353003 )

3. Nunc $60 \mathrm{~mm}$ dish with HydroCell surface (Thermo Fisher Scientific, catalog number: 174912)

4. Disposable micro homogenizer (TaKaRa Bio, TaKaRa BioMasher Standard, catalog number: 9791A)

5. Aerosol resistant tip (ART 1000 REACH tips) (Thermo Fisher Scientific, model: 2079)

6. Membrane filter (EMD Millipore, Millex-GV 0.22um, 33mm)

7. Dissecting microscope (Olympus, model: SZH10)

8. Centrifuge (KUBOTA, model: 5220)

9. $\mathrm{CO}_{2}$ incubator (set at $37{ }^{\circ} \mathrm{C}$ and $5 \% \mathrm{CO}_{2}-95 \%$ air)

10. Reciprocal shaker (TAITEC, model: NR-1)

11. Laminar flow hood (W800 x H1050 x D500 mm) (Panasonic Corporation, SANYO, model: MCV-710ATS)

12. Scissors (NAPOX B-5H, $154 \mathrm{~mm}$; NAPOX B-1112H, $110 \mathrm{~mm}$ ), fine forceps (NAPOX A-5, $110 \mathrm{~mm}$; NAPOX MA-45, $110 \mathrm{~mm}$ ), spatula (Laboran 9-891-03, $180 \mathrm{~mm}$ )

13. Ice bucket

\section{Procedure}

1. Dissect the brain from newborn mice under Laminar flow hood (Figure 1). Spray $70 \%$ ethanol upon newborn mice and cut the head (Figure 2A). Make small incisions (Figure 2B, arrows) and remove the skin. Then, carefully remove the skull with forceps and expose the brain (Figure 2C). 


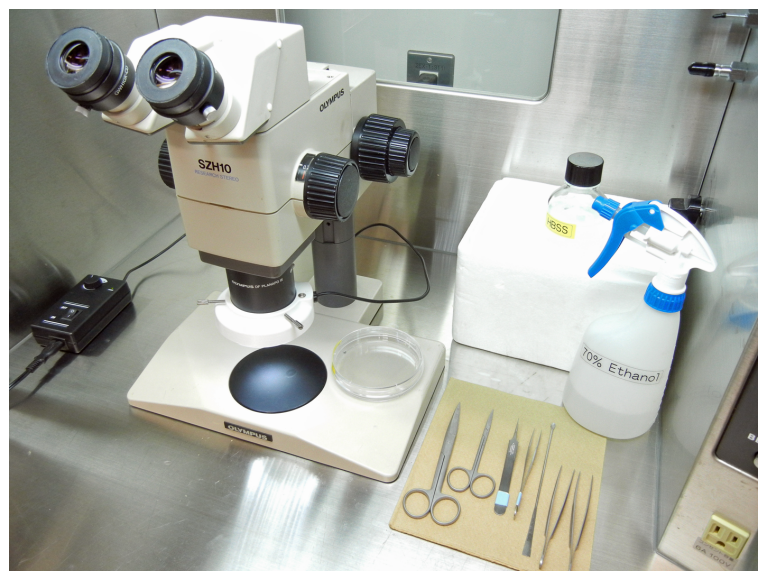

Figure 1. Dissecting equipments arranged in a Laminar flow hood
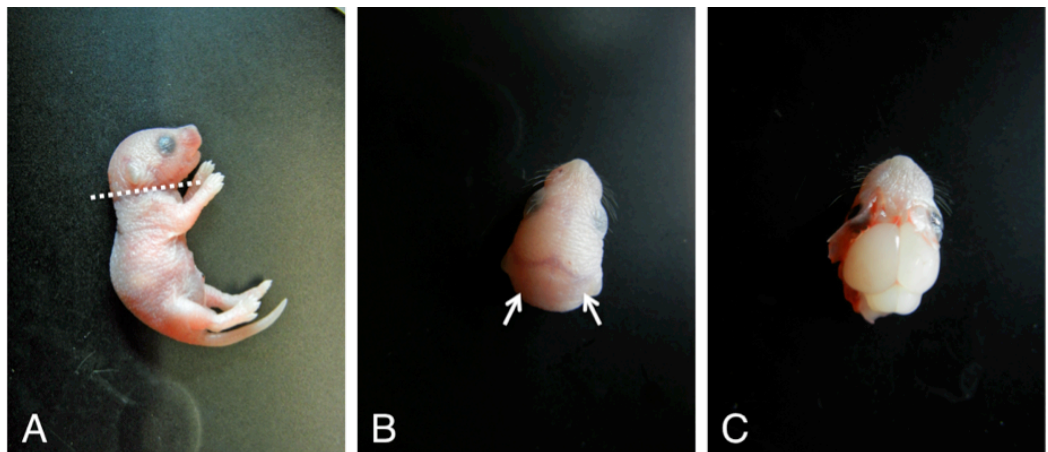

Figure 2. Dissection procedures to obtain neonatal mouse brain

2. Scoop the brain by a small spatula and place them in ice cold HBSS $(10 \mathrm{ml}$ in $100 \mathrm{~mm}$ dish, Figure $3 \mathrm{~A}$ ). By using fine forceps, remove meninges under dissecting microscope (Figure 3B-C).
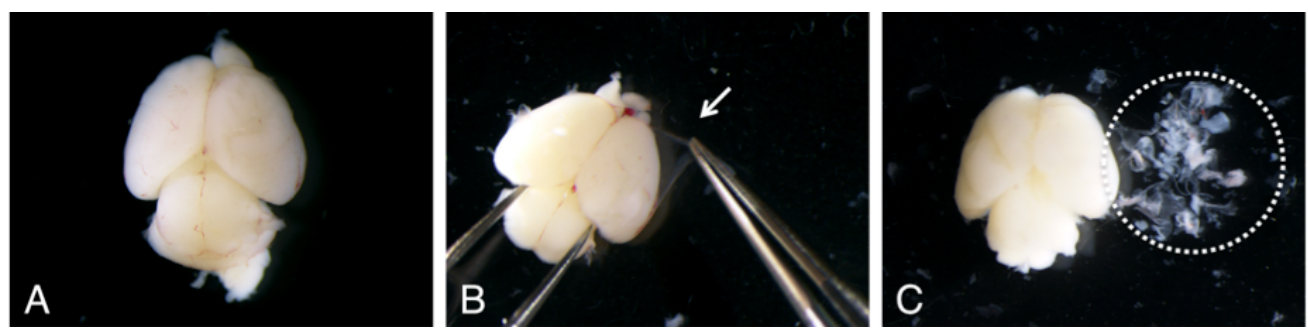

Figure 3. Removal of meninges (B: arrow) from neonatal mouse brain under dissecting microscope. After removal of meninges, the brain becomes whitish color (C).

3. Place cortices in sterilized disposable micro homogenizer and centrifuge at $5000 \times \mathrm{g}$ for 30 $\sec$ at $4{ }^{\circ} \mathrm{C}$. 
4. Pipet the minced tissue with $2 \mathrm{ml}$ of D-PBS containing $1 \mathrm{mM}$ EDTA, $100 \mu \mathrm{g} / \mathrm{ml}$ trypsin, and $400 \mu \mathrm{g} / \mathrm{ml}$ DNase I until evenly homogenized and place them in a $15 \mathrm{ml}$ Conical Centrifuge Tube.

5. Incubate for $15 \mathrm{~min}$ at $37^{\circ} \mathrm{C}$ in an incubator with constant agitation using a reciprocal shaker at $50 \mathrm{rpm}$. Add $1 \mathrm{ml}$ of FBS, then gently pipet up and down to help the dissociation by using aerosol resistant tip to avoid contamination. Stand tubes for 2 min at $25^{\circ} \mathrm{C}$ and collect supernatant by pipetting. Avoid to suck any visible tissue fragments.

6. Centrifuge cell suspensions at $200 \times \mathrm{g}$ for $5 \mathrm{~min}$ at $25^{\circ} \mathrm{C}$ and resuspend the pellet in Neurosphere basal medium $(10 \mathrm{ml})$ by pipetting.

7. Centrifuge the cell suspension at $200 \times g$ for $5 \mathrm{~min}$ at $25^{\circ} \mathrm{C}$. Discard the supernatant, resuspend in $5 \mathrm{ml}$ of Neurosphere basal medium at $25^{\circ} \mathrm{C}$ and transfer it into Nunc $60 \mathrm{~mm}$ dishes with HydroCell Surface. Culture the cells at $37^{\circ} \mathrm{C}$ in humidified $\mathrm{CO}_{2}$ incubator $(5 \%$ $\mathrm{CO}_{2}-95 \%$ air).

8. Refill $0.5 \mathrm{ml}$ of Neurosphere basal medium everyday.

9. After 5-7 days, neurospheres with variable sizes (50-100 um in diameter) are formed in the culture (Figure 4). Centrifuge neurosphere suspensions at $200 \times g$ for $5 \mathrm{~min}$ at $25^{\circ} \mathrm{C}$, discard the supernatant, and resuspend in $2 \mathrm{ml}$ of Accutase at $37^{\circ} \mathrm{C}$ for $10 \mathrm{~min}$.

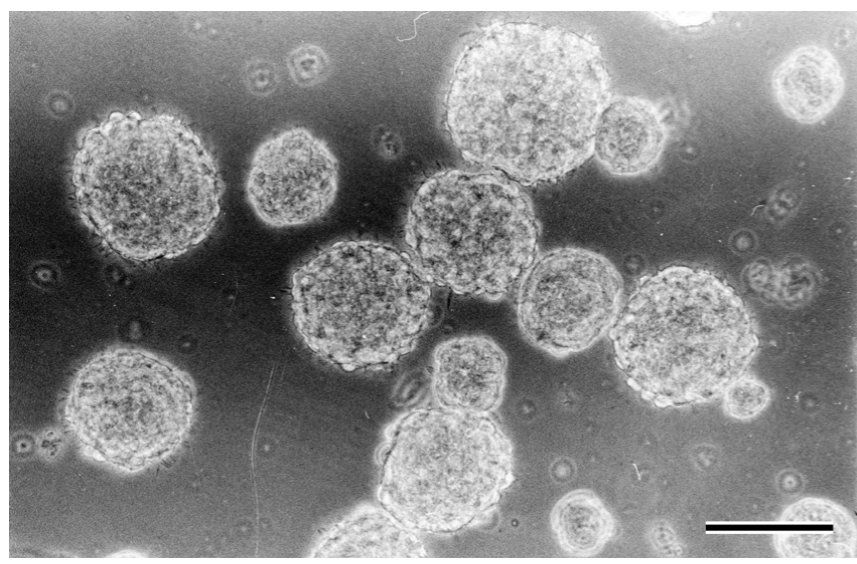

Figure 4. Neurosphere formation in Neurosphere basal medium after 5 days of culture. Scale bar $=100 \mathrm{um}$

10. Gently pipet up and down (about ten times) using aerosol resistant tip to dissociate into single cells. Check the cells under microscope for successful dissociation. Add $12 \mathrm{ml}$ of HBSS and centrifuge at $200 \times \mathrm{g}$ for $5 \mathrm{~min}$ at $25^{\circ} \mathrm{C}$. Resuspend the pellet in $10 \mathrm{ml}$ of Neurosphere basal medium at $25^{\circ} \mathrm{C}$ and subculture into new Nunc $60 \mathrm{~mm}$ dishes with HydroCell Surface at $1: 4$ split ratio (i.e. $25 \%$ of the harvested cells are seeded into the new dish with same size). Refill $0.5 \mathrm{ml}$ of Neurosphere basal medium everyday. The 
neurospheres are subcultured at 4-6 day intervals.

\section{Recipes}

1. Deoxyribonuclease I (DNase I)

Dissolved at $4 \mathrm{mg} / \mathrm{ml}$ in D-PBS

Sterile filtered $(0.22 \mu \mathrm{m})$

Aliquoted $(4 \mathrm{ml})$ and stored at $-20^{\circ} \mathrm{C}$

Use within 6 months

2. Epidermal growth factor human (EGF)

Dissolved at $50 \mathrm{\mu g} / \mathrm{ml}$ in sterile DMEM/F12 Ham containing $1 \%$ BSA

Aliquoted $(100 \mu \mathrm{l})$ and stored at $-20^{\circ} \mathrm{C}$

Use within 6 months

3. Fibroblast growth factor-basic human (bFGF)

Dissolved at $50 \mathrm{\mu g} / \mathrm{ml}$ in sterile DMEM/F12 Ham containing $1 \%$ BSA

Aliquoted $(50 \mu \mathrm{l})$ and stored at $-20^{\circ} \mathrm{C}$

Use within 6 months

4. Bovine serum albumin (BSA)

Dissolved at $300 \mathrm{mg} / \mathrm{ml}$ in D-PBS

Sterile filtered $(0.22 \mu \mathrm{m})$

Stored at $4{ }^{\circ} \mathrm{C}$

Use within 6 months

5. Neurosphere basal medium

$\begin{array}{lll}\text { Reagents } & \text { Volume } & \text { Final conc. } \\ \text { DMEM/F12 Ham } & 487.33 \mathrm{ml} & \\ \text { EGF } & 500 \mu \mathrm{l} & 50 \mathrm{ng} / \mathrm{ml} \\ \text { bFGF } & 500 \mu \mathrm{l} & 50 \mathrm{ng} / \mathrm{ml} \\ \text { BSA } & 1.67 \mathrm{ml} & 0.1 \% \\ \text { N2 supplement } & 5 \mathrm{ml} & 1 \% \\ \text { Penicillin-streptomycin } & 5 \mathrm{ml} & 100 \mathrm{IU} / \mathrm{ml} \text { and } 100 \mu \mathrm{g} / \mathrm{ml} \text {, respectively }\end{array}$

6. Trypsin

Dissolved at $1 \mathrm{mg} / \mathrm{ml}$ in D-PBS containing $10 \mathrm{mM}$ EDTA

Sterile filtered $(0.22 \mu \mathrm{m})$

Aliquoted $(4 \mathrm{ml})$ and stored at $-20^{\circ} \mathrm{C}$

Use within 6 months

For the dissociation of minced brain tissue, mix the reagents as follows 


$\begin{array}{lcc}\text { Reagents } & \text { Volume } & \text { Final conc. } \\ \text { Trypsin } & 1 \mathrm{ml} & 100 \mu \mathrm{g} / \mathrm{ml} \\ \text { DNase I } & 1 \mathrm{ml} & 400 \mu \mathrm{g} / \mathrm{ml} \\ \text { D-PBS } & 8 \mathrm{ml} & \end{array}$

\section{Acknowledgments}

This protocol was adapted from our previously published paper: Iwamaru et al. (2013). This work was supported by a Grant-in-Aid from the BSE and Other Prion Disease Control Project of the Ministry of Agriculture, Forestry, and Fisheries of Japan and by a Grant-in-Aid for Young Scientists (category B) from the Ministry of Education, Culture, Sports, Science, and Technology of Japan.

\section{References}

1. Gage, F. H. (2000). Mammalian neural stem cells. Science 287(5457): 1433-1438.

2. Iwamaru, Y., Takenouchi, T., Imamura, M., Shimizu, Y., Miyazawa, K., Mohri, S., Yokoyama, T. and Kitani, H. (2013). Prion replication elicits cytopathic changes in differentiated neurosphere cultures. J Virol 87(15): 8745-8755. 